\title{
Activity-Dependent Structural Dynamics of Insect Sensory Fibers
}

\author{
H.-J. Pflüger,' S. Hurdelbrink,' A. Czjzek,' and M. Burrows² \\ 'FU Berlin, FB Biologie, Institut für Neurobiologie, D-14195 Berlin, Germany, and 'Department of Zoology, University of \\ Cambridge, Cambridge, CB2 3EJ, United Kingdom
}

This report analyses the role of neuronal activity in shaping the axonal arborizations of sensory neurons from individually identified filiform hairs on the prosternum of locusts (Locusta migratoria), and their connections with a pair of identified interneurons (A411). Afferents from lateral filiform hairs terminate in the ipsilateral neuropil and connect only with the ipsilateral interneuron in all instars. Afferents from ventral filiform hairs possess ipsi- and contralateral branches and make monosynaptic connections with both interneurons in first instars. In later instars, the ipsilateral branch, and its synaptic connection to the ipsilateral interneuron, is gradually reduced until it is lost in the adult, whereas the contralateral branch, and its synaptic connection with the contralateral interneuron, is strengthened. Therefore, after an initial overgrowth of fibers and synapses, segregation of fibers occurs involving the loss of synaptic connections. This loss of branches and synapses was prevented by immobilizing a subpopulation of ventral and lateral filiform hairs, or each group independently, so that their normal activity was blocked. In such treated animals afferents from ventral filiform hairs retain their ipsi- and contralateral branches until adulthood. We therefore conclude that afferent activity plays an important role in shaping the final structure and connectivity of afferents, as neither the peripheral position of the receptors nor the hormonal environment was changed by these manipulations.

[Key words: insects, mechanoreceptors, sensory systems, intracellular staining, synaptic connections, competition]

In forming the precise connections required of a fully functional adult organism, neurons must first grow into the correct area by selecting a specific pathway (pathway selection; Goodman and Shatz, 1993), and then select the correct target among many neurons (target selection; Goodman and Shatz, 1993). Initially, supernumerary branches are segregated through processes of refinement (reviewed in Purves and Lichtman, 1985; Goodman and Shatz, 1993), meaning that individual neurons must retract

\footnotetext{
Received Dec. 30, 1993; revised Apr. 25, 1994; accepted May 11, 1994.

The support of H.-J.P. by a grant from the DFG (Pf 128/6-3 and Pf 128/6-4) and of H.-J.P. and M.B. by a grant of the HFSP-Organisation is gratefully acknowledged. Many results were part of S. Hurdelbrink's and A. Czjzek's Diplom theses at the Freie Universităt Berlin. We thank Heike Wolfenberg for expert technical assistance, and Paul Stevenson, Berlin, and Rodney K. Murphey, Amherst, for numerous helpful suggestions and lively discussions. We are also indebted to the two anonymous referees for their suggestions.

Correspondence should be addressed to H.-J. Pflüger, FU Berlin, FB Biologie, Institut für Neurobiologie, Königin-Luise Strasse 28-30, D-14195 Berlin, Germany.

Copyright (C) 1994 Society for Neuroscience $0270-6474 / 94 / 146946-10 \$ 05.00 / 0$
}

branches and eliminate transient synapses (Purves and Lichtman, 1980). After such successful "address selection" (Goodman and Shatz, 1993) subsequent developmental processes of "maturation" (refinement) must occur to ensure proper functioning in adult behavior (Crepel et al., 1976; Jackson and Parks, 1982).

Pathway and target selection probably involves guidance through gradients of factors released by the target neurons, and the recognition of specific surface molecules. By contrast, the processes of refinement including those of maturation probably require neuronal activity (reviewed in Goodman and Shatz, 1993). For example, they shape the final uniterminal innervation of the vertebrate neuromuscular synapse (Redfern, 1970; Brown et al., 1976; Thompson, 1983; reviewed in Thompson, 1986), the ocular dominance columns in the primary visual cortex of mammals (Hubel and Wiesel, 1963; LeVay et al., 1978, 1980; Shatz and Stryker, 1978; Goldman-Rakic, 1981), and may also be involved in the formation of the barrel fields in rodent somatosensory cortex (Schlaggar et al., 1993).

The changes of structure and connectivity of neurons through processes dependent on the activity of neurons, were long regarded as an exclusive domain of vertebrates (Easter et al., 1985). More recently, however, similar mechanisms have been found to act in invertebrate nervous systems (Murphey, 1986a; Lnenicka and Murphey, 1989). In the crustacean neuromuscular synapse, physiological and ultrastructural changes can be induced by activity similar to those in the vertebrates (Lnenicka and Atwood, 1985; Pahapill et al., 1985; Lnenicka et al., 1986, 1991), and pruning of neuronal processes and synaptic sites during a period of early development has also been reported for leech neurons (Kuwada and Kramer, 1983; Wallace, 1984; Gao and Macagno, 1987a,b). In crickets, connections between cercal filiform hair afferents and two identified interneurons are remodeled during postembryonic life by seemingly competitive interactions (Murphey and Lemere, 1984; Murphey, 1986b; Shepherd and Murphey, 1986; Chiba et al., 1988; Lnenicka and Murphey, 1989), but the establishment of the normal connectivity does not require afferent activity (Chiba and Murphey, 1991). Although similar activity-dependent mechanisms act on developing invertebrate and vertebrate nervous systems, the real advantage of invertebrate nervous systems, which lies in the ability to work with identifiable neurons, has not yet been fully exploited.

Here, we report on a specific group of identified filiform hair receptors on the neck of a locust that comprise part of the receptive field of an identified postsynaptic interneuron called A4I1 (Pflüger, 1984; Pflüger and Burrows, 1990). In an adult locust there are 150 of these wind-sensitive hairs, the majority of which are less than $100 \mu \mathrm{m}$ long, except 15 , which range from 
350 to $750 \mu \mathrm{m}$. The length of one of these hairs correlates with its date of appearance and with the efficacy of the direct, monosynaptic connections made by its single afferent neuron with an A4I1 interneuron (Pflügcr and Burrows, 1990). An A4I1 interneuron makes excitatory connections with motor neurons that control the angle of twist of the wings (Burrows and Pflüger, 1992), and may therefore play a role in controlling steering during flight.

Only adult locusts possess fully functional wings but the hairs, the interneurons, and the motor neurons are already present in newly hatched first larval instars. The ability to identify specific receptors and their postsynaptic target allowed us to stain selected receptors during postembryonic development and therefore to follow changes in the patterns of their central projections and connections. We demonstrate that these sensory neurons show remarkable structural dynamics during normal development involving loss of axon collaterals, and in parallel remodeling of their synaptic connections with A4II. Disturbing the normal activity of these receptors changes the pattern of their central projections and interferes with the normal development of A4Il's receptive field. This provides evidence that normal activity plays a decisive role in shaping the adult central projections of afferent fibers and in maturation of a receptive field.

\section{Materials and Methods}

All experiments were carried out on Locusta migratoria obtained from crowded colonies at the Free University of Berlin or at the University of Cambridge. Animals were cooled for $10 \mathrm{~min}$ before any dissections or manipulations were performed.

Determination of prosternal hair location. To determine the number and appearance of filiform hairs in the larval instars, three animals were isolated after hatching and kept separately through all larval instars to the adult stage. After each moult the remaining exuvia, which is a perfect replica of the old cuticle with its complement of exteroceptors, was examined by a stereo microscope. Measurements of hair length, hair numbers, and location could thus be compared with those of the previous exuvia.

Staining of receptors. A single filiform prosternal hair was selected and then, in an early instar, its shaft was pulled away with forceps or, in a later instar, was cut close to its base with a razor blade, leaving the underlying sensory apparatus intact. A broken microelectrode filled with $6 \%$ hexamine cobaltic chloride was then placed over the cut hair shaft, or base, and a 500-msec-long depolarizing current (50-90 nA) was applied at $1 \mathrm{~Hz}$ for $15-45 \mathrm{~min}$, depending on the size of the animal. After a diffusion time of $2-3 \mathrm{hr}$, the prothoracic ganglion was removed, the cobalt ions were precipitated as the sulphide, and the ganglion was fixed in $4 \%$ neutral formaldehyde for $45 \mathrm{~min}$. Ganglia were then silver intensified (Bacon and Altman, 1977), dehydrated, and cleared in methyl salicylate. Central projections of the sensory neurons from filiform hairs were drawn with the aid of a drawing tube attached to a Zeiss Axiophot microscope. The data on larval instars are based on successful stains of hairs in 270 animals. The projections of hairs in adults were pooled from this and previously published work (Pflüger, 1980; Pflüger and Taut2, 1982; Watson and Pflüger, 1984). Some selected camera lucida drawings were magnified so that the total length of afferent projections could be measured with the aid of a simple map measurer.

Intracellular recordings. To record intracellularly close to the spike initiation zone of the A4I 1 interneuron and simultaneously from identified prosternal hair receptors, the locust was prepared as described in Pflüger and Burrows (1990). In brief, the locust was dissected ventrally and a wax-coated platform placed beneath the prothoracic ganglion, leaving the whole prosternum intact. Glass micropipettes were filled with $2 \mathrm{M}$ potassium acetate solution and had resistances up to $60 \mathrm{M} \Omega$. Electrode penetration was eased by applying a $1 \%$ solution of protease (type XIV, Sigma) for about 1 min, depending on the age of the animal. To record the spikes of identified filiform hair receptors, the shaft of the selected hair was cut near its base, and a broken glass micropipette filled with locust saline (Hodgson et al., 1955) placed over it. Movements of the recording microelectrode evoked action potentials in the single sensory neuron associated with each filiform hair. The A4I I interneuron was identified by its characteristic response to air blown over the prosternum (Pflüger, 1984). No other interneurons with the same response properties are known. Furthermore, the interneuron could be stained by injection of cobalt to confirm its unique anatomy (Pflüger, 1984). Thus, both the afferent spike from an identified receptor and the EPSP it evoked in an identified interneuron (A4I1) could be recorded simultaneously.

Disrupting normal development. The natural activation of filiform hair receptors on one-half of the prosternum, which is composed of one lateral proepisternum and one-half of the ventral probasisternum, was altered either by covering them with wax or by shaving them at their base (treated side). The other prosternal half was left intact (untreated side). These manipulations were carried out immediately after hatching, and repeated immediately after each larval molt. The period from hatching to adulthood, during which animals were monitored regularly, lasted between 20 and $25 \mathrm{~d}$ in our breeding conditions. Then, central projections from ventral filiform hairs were revealed iontophoretically 1-28 $\mathrm{d}$ after the final molt to adulthood. In some animals, only one lateral proepisternum was treated as described above. About $70 \%$ of the treated first instar larvae survived all manipulations until adulthood.

\section{Results}

\section{Normal development of prosternal receptors}

The prosternum, a ventral cuticular plate in the prothoracic segment, is divided into the lateral proepisternum, ventral probasisternum, and posterior spinasternite (Albrecht, 1953; Fig. 1 , lower right insets). It is covered with numerous stiff tactile hairs, and with flexible filiform hairs. The latter, found only on the lateral proepisternum and ventral probasisternum (called lateral and ventral hairs), are sensitive to air particle movement, have thin hair shafts, and possess light to dark brown pigmented bases. About $10 \%$ of the adult complement of filiform hairs is already present in a newly hatched first instar larva, with the majority (55\%) appearing in the final two instars (Fig. $1 A$ ). In the first instar there are approximatcly 30 hairs (mcan \pm SD, $32.3 \pm 1.25 ; n=3)$, and in the adult, approximately $300(307.7$ $\pm 12.9 ; n=3$ ), of which $64.5 \%$ are up to $100 \mu \mathrm{m}, 26.7 \%$ up to $350 \mu \mathrm{m}$, and $8.8 \%$ up to $750 \mu \mathrm{m}$ long. New hairs are added at each molt, and with each molt the length of the hair shafts increases and the pigmentation of their bases becomes darker. At each larval instar individual filiform hairs can be identified since they maintain their peripheral location and relative size in relation to their neighbors. For example, in first instar larvae 10 filiform hairs, two lateral and eight ventral ones, can be identified on each side of the prosternum, and the same hairs can still be identified in the adult (Fig. $1 B, C$ ). This study therefore concentrates on the development of this population of 10 identifiable filiform hairs on both sides of the prosternum; the ventral hairs are numbered $1-8$, and the lateral hairs 9-10 (Fig. $1 B, C)$. In adults, these hairs make the strongest synaptic connections with A4I1 (Pflüger and Burrows, 1990).

\section{Development of central projections of prosternal hairs}

Adult animals. Figure 2 shows examples of projection patterns of afferents from long filiform hairs in adults. The afferents from the longest lateral hairs ( $\mathrm{L}$ and $\mathrm{R}$ hair 9 in Fig. 2) project only to the ipsilateral neuropil ( $n=50$ animals). Correspondingly, the afferents connect only with the A4I 1 interneuron whose axon is ipsilateral to their projections (Pflüger and Burrows, 1990; see also schematic drawing in Fig. $2 B$ ). Afferents from ventral filiform hairs ( $\mathrm{R}$ hair 3 and $\mathrm{L}$ hair 7) project only to the contralateral neuropil ( $n=50$ animals), and correspondingly make connections with the contralateral A4I1 interneuron (Pflüger and Burrows, 1990; see also Fig. 2B).

Larval instars. The progressive changes in the projections of 


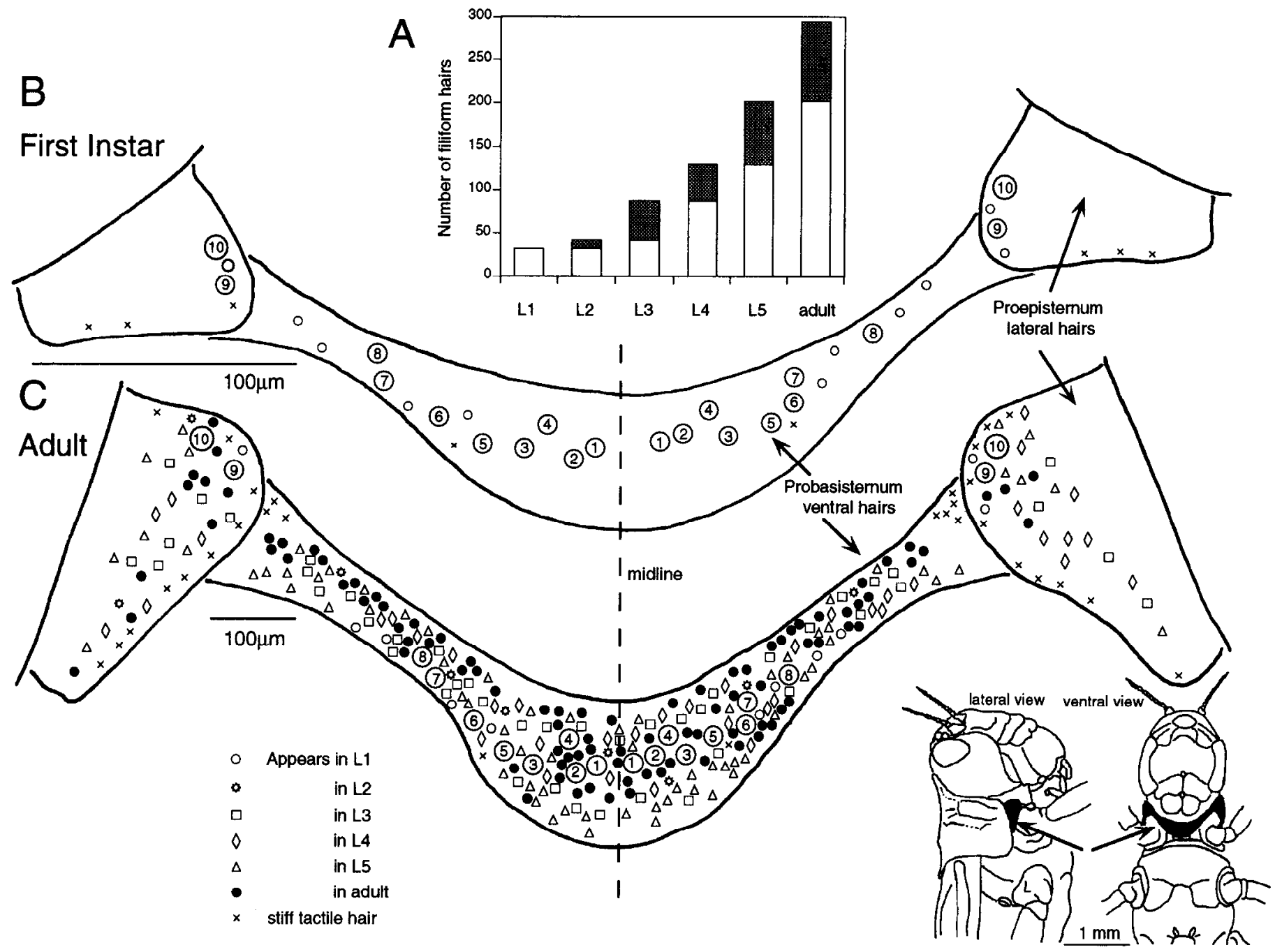

Figure 1. A, Increase in the number of prosternal filiform hair receptors during larval instars. The shaded bars show the number of hairs added at each indicated instar. $B$ and $C$, Distribution of filiform hairs of one individual in a first larval instar $(B)$, and in the adult $(C)$. Inset shows location of proepisternum in a lateral view (left, arrow pointing to black area) and probasisternum in a ventral view (right, arrow pointing to black area).

two selected hairs were followed from the first instar to the adult (Fig. 3). One, lateral hair 9, on the left proepisternum has an ipsilateral projection throughout development (Fig. 3, left column). By contrast, the other, ventral hair 1 on the left probasisternum has both an ipsi- and contralateral projection until the fifth instar, but only a contralateral projection in the adult (Fig. 3 , right column). There are thus marked differences in the development of the projections from different hairs, with some loosing an array of branches from their projections. We examine further only the ventral hairs that show the most dramatic changes in their projection pattern throughout development. Examples of projection patterns of the sensory neurons from five of these identified ventral hair receptors (hairs $1-3,5$, and 7) during postembryonic development are shown in Figure 4. During early instars the axon of each afferent projects to both ipsi- and contralateral neuropil. The ipsilateral projection is progressively retracted in later instars, until it is completely absent in the adult. During this retraction process the ipsilateral axon collateral loses numerous beaded side branches such that in later instars it hecomes thin and smooth. The more distal the ventral hair is situated on the probasisternum, the earlier is the ipsi- lateral branch lost. For example, ventral hairs 5 and 7 lose most of their branches from the ipsilateral collateral by $\mathrm{L} 3$, and the collateral itself is lost by L4. By contrast, ventral hairs such as 1 and 2 close to the midline lose their ipsilateral projections only in L5 or at the molt to the adult. While this loss of the ipsilateral projection is occurring, the general trend is for the contralateral axon collateral to thicken and to develop more side branches. Both contralateral and ipsilateral branches project posteriorly within homologous tracts and therefore anatomically overlap with the postsynaptic A4I1 interneuron.

\section{Physiological connections with the A4II interneuron}

To test if the different patterns of projections during development are correlated with different patterns of connections with the A4I1 interneurons, simultaneous recordings were made from at least five identified ventral filiform hairs and an A4I1 interneuron in third and fourth instars, and in the adult (three animals each; Fig. 5). The recording arrangement is shown schematically for an adult animal in Figure $5 \mathrm{~A}$. Ventral hairs 1 on the left and on the right side of the probasisternum both have an ipsilateral and a contralateral projection in $\mathrm{L} 3$ and $\mathrm{L} 4$, and 


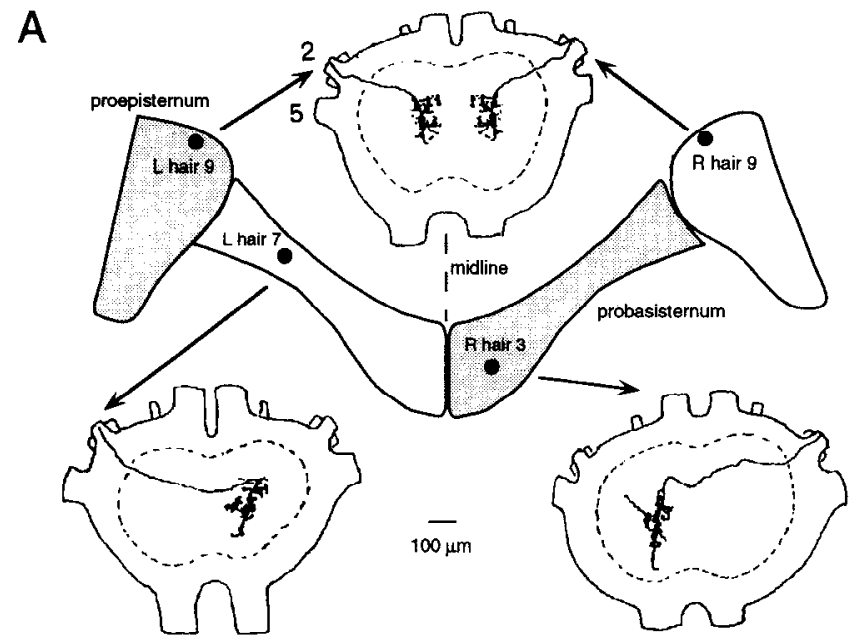

B

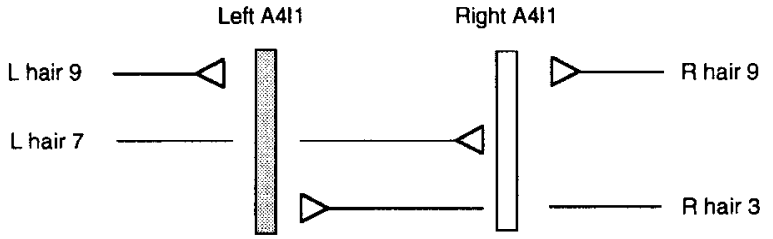

Figure 2. Projection $(A)$ and connectivity $(B)$ patterns of selected lateral and ventral filiform hairs on left and right proepisternum ( $L$ and $R$ hair 9 ), and on left and right probasisternum ( $L$ hair 7 and $R$ hair 3). Shaded area on the prosternum shows receptive field of the respective interneuron $(B)$. Dashed lines within ganglia show the outline of neuropil. $B$, Diagram of the connections of these afferents with the left and right A4I1 interneurons. The bars represent the axons of the interneurons, and the triangles, excitatory connections from the hair afferents.

synapse with the same $\Lambda 4 \mathrm{I} 1$ interneuron (Fig. $5 B, C$ ). This indicates that the afferent from each ventral hair 1 connects with both the left and the right A4I1 interneuron, so that both the ipsilateral and contralateral projections must establish synaptic connections with the interneurons. The connections of both the left and the right ventral hairs seem to be monosynaptic, as their latencies are in accord with all the other hairs that make connections, and which have been studied in detail (Pflüger and Burrows, 1990). They are regarded as monosynaptic because for an individual hair their central latencies are constant and short (1.2-1.3 msec), and each afferent spike is consistently followed by an EPSPs in the interneuron. The EPSP from the ipsilateral hair in L3 and L4, however, is smaller than that from the contralateral hair. In L5, a connection from an ipsilateral ventral hair 1 can be found in only some animals. In the adult, no connections from the ipsilateral hair 1 are found, but the connection from the contralateral hair is now powerful enough to make the interneuron spike (Fig. 5D, arrow and inset). Correspondingly, in the adult, the ipsilateral projection of ventral hair 1 is lost and only the contralateral projection persists.

Similar patterns of connections were found for other ventral hairs. In L3, both ipsilateral and contralateral connections are made by ventral hairs $2-4$, but no ipsilateral connections were found for hairs 6 and 7 , although these afferents still possessed an ipsilateral projection (see Fig. 4). These ipsilateral branches, however, appeared smooth and already much reduced without blebs or arborizations. This indicates that functional synapses

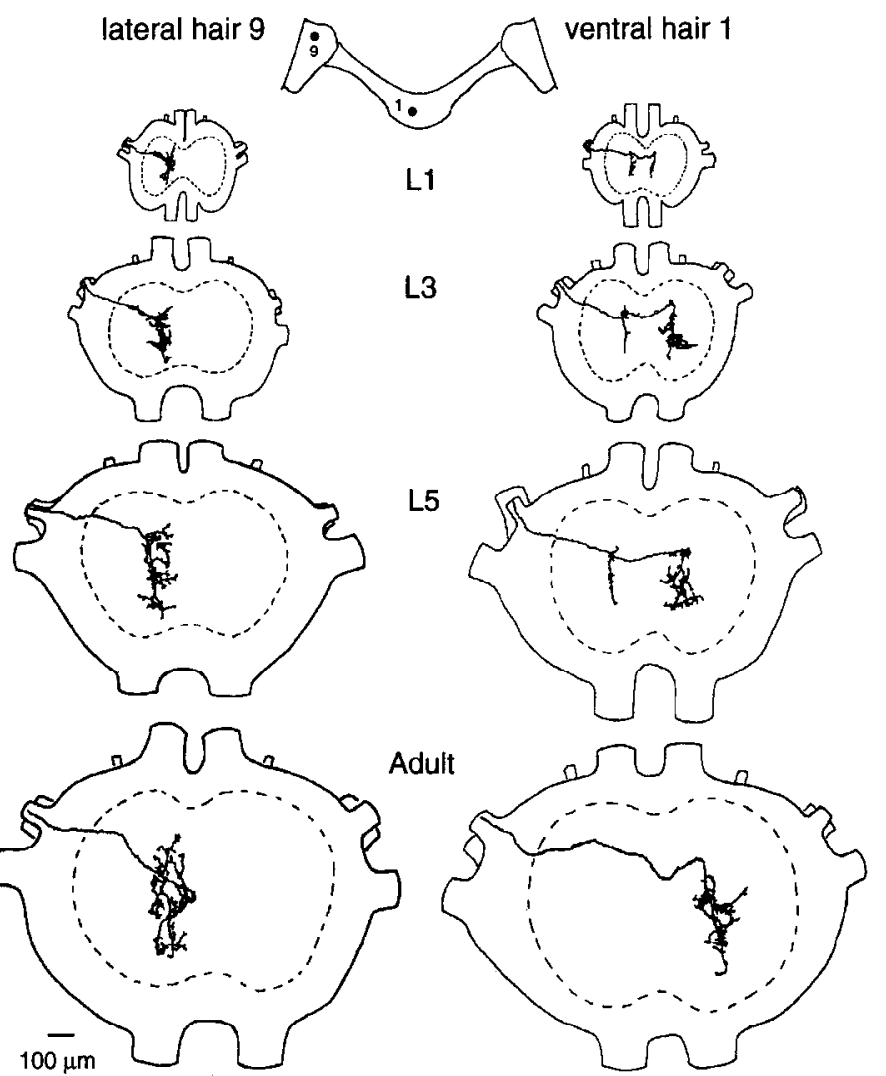

Figure 3. Projection patterns of two selected filiform hairs, lateral hair 9 and ventral hair 1 , in first $(L 1)$, third $(L 3)$, and fifth $(L 5)$ instars and in the adult.

are lost at a time when such anatomical changes occur. In L4, no ipsilateral connections were found for ventral hairs $3-7$, and in L5 no ipsilateral connections were found except the occasional ones made by ventral hair 1 .

\section{Disrupting normal development}

To see if the projection patterns were altered by changing the afferent activity, two manipulations were performed to block normal activity during development. Immediately after hatching in the first larval instar, and then repeated immediately after each larval molt, the filiform hairs either were shaved at their base or were immobilized with wax. In such treated animals extracellular recordings from the sensory nerve revealed no afferent spikes in response to air currents over the prosternum. Normally, the receptors have a high sensitivity and respond to air particle movements in a purely phasic manner (Pflüger and Tautz, 1982). Therefore, both manipulations suppressed activity in the afferents from the treated hairs. The manipulations, however, did not destroy the sensory or the accessory cells associated with a filiform hair, because after each molt a new hair with a shaft almost as long as that of its homolog on the untreated side was generated, and the sensory neuron could be recorded and stained. Furthermore, the manipulations did not alter the peripheral position of the filiform hair relative to its neighbors. The only anatomical differences between filiform hairs from the treated and untreated side in the adult were that the former had slightly thinner hair shafts and the cuticle at their base was less pigmented. Figures 6 and 7 show the results of these manipulations and Figure 8 summarizes and quantifies them. 
Figure 4. Projection patterns of selected ventral filiform hairs in normal animals. $A$, Schematic drawing of right half of prosternum showing the location of hairs. $B$, Projection patterns of five selected ventral filiform hair afferents from the indicated larval instars $(L 1, L 3, L 4, L 5)$, and the adult. Note the different scales.

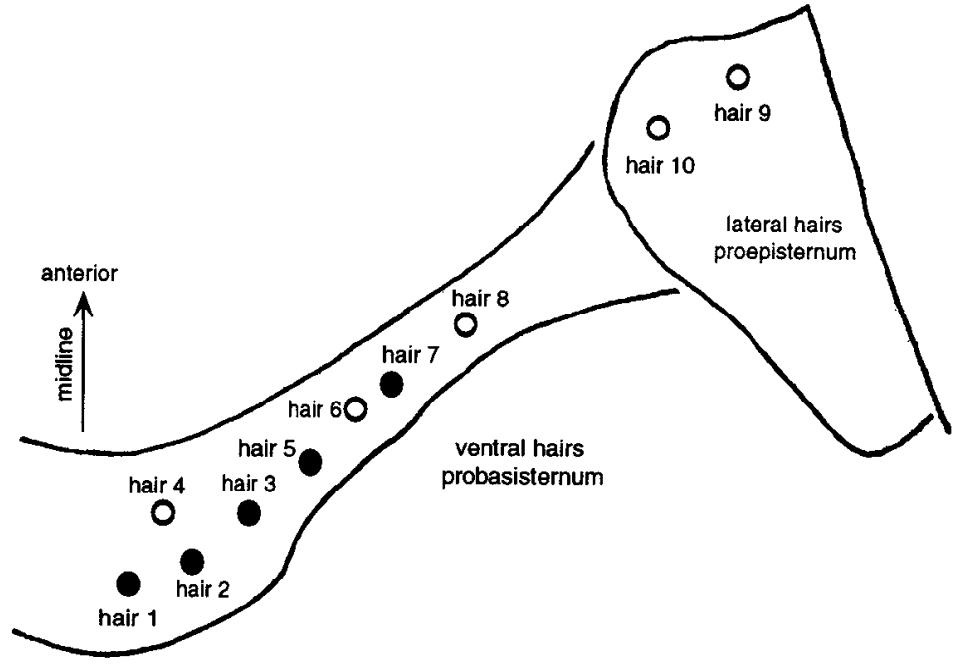

B hair 1

hair 2

hair 3

hair 5

hair 7
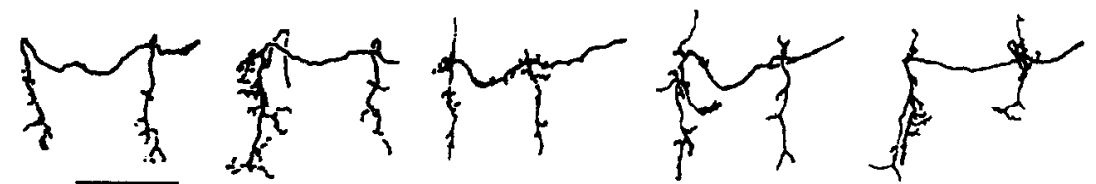

$100 \mu \mathrm{m}$

L3
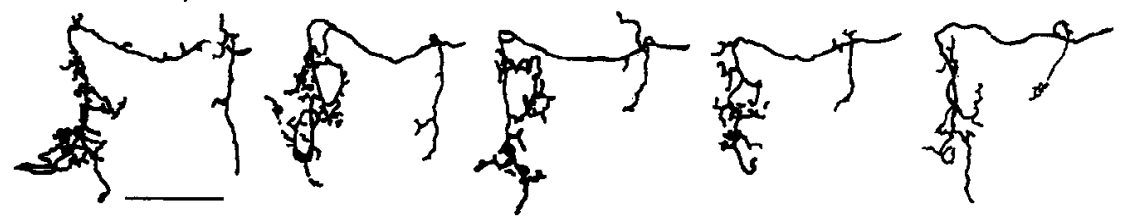

L4
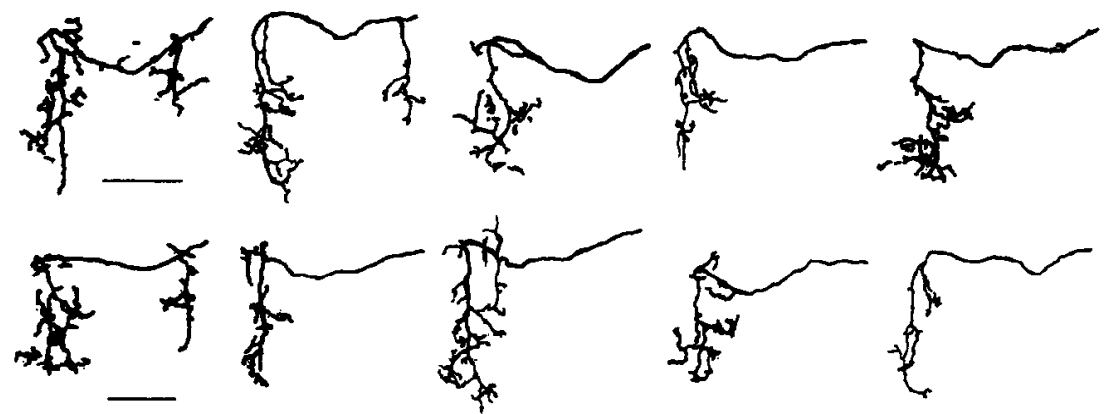

adult
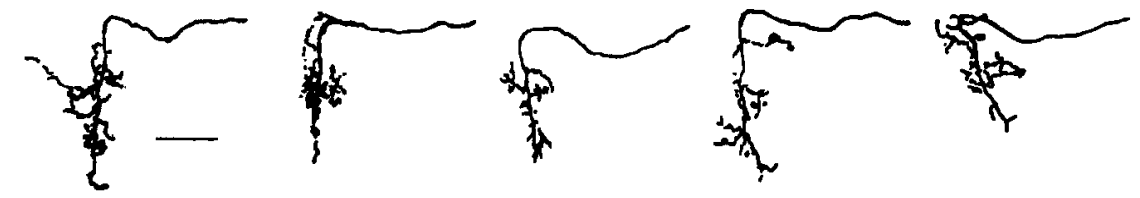

Immobilizing the right ventral and lateral hairs. Animals whose ventral and lateral hairs were immobilized on the right prosternal half showed dramatic changes in the projection patterns of ventral filiform hairs from both the previously treated and the untreated sides (Fig. 6). In control adult animals, all ventral hairs had only contralateral projections (Figs. $6 A ; 8 A, 100 \%$, first column), whereas those of treated adult animals had both ipsi- and contralateral projections. On the untreated side, 74\% of the 49 examined ventral filiform hairs had both ipsi- and contralateral projections (Fig. $6 B, C$ ), and the remaining $26 \%$ had only contralateral projections (Fig. $8 A$, third column). On the treated side, $65 \%$ of the 37 ventral hairs examined had both ipsi- and contralateral projections (Fig. $6 D, E$ ), and the remaining $35 \%$ had only contralateral projections (Fig. $8 \mathrm{~A}$, second column). The projections in Figure $6 B-E$ represent the extremes of what was found, afferents have either a well-developed contralateral axon collateral and a thinner ipsilateral axon collateral with few side branches (Fig. $6 B, D$ ), or both well-developed contralateral and ipsilateral projections (Fig. 6C,E).

These results suggest that activity-dependent processes play a role in shaping the projections of sensory neurons from ventral hairs. Normal activity throughout larval development elimi- 

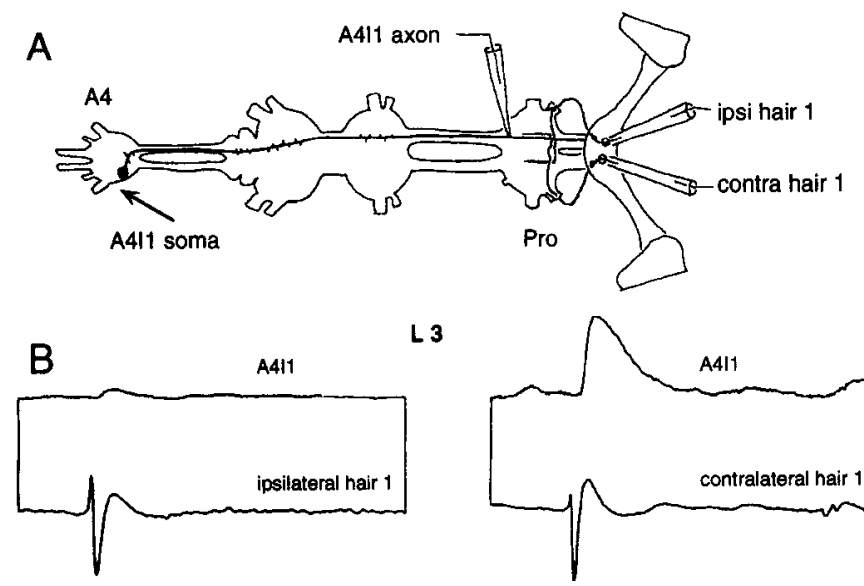

L 3
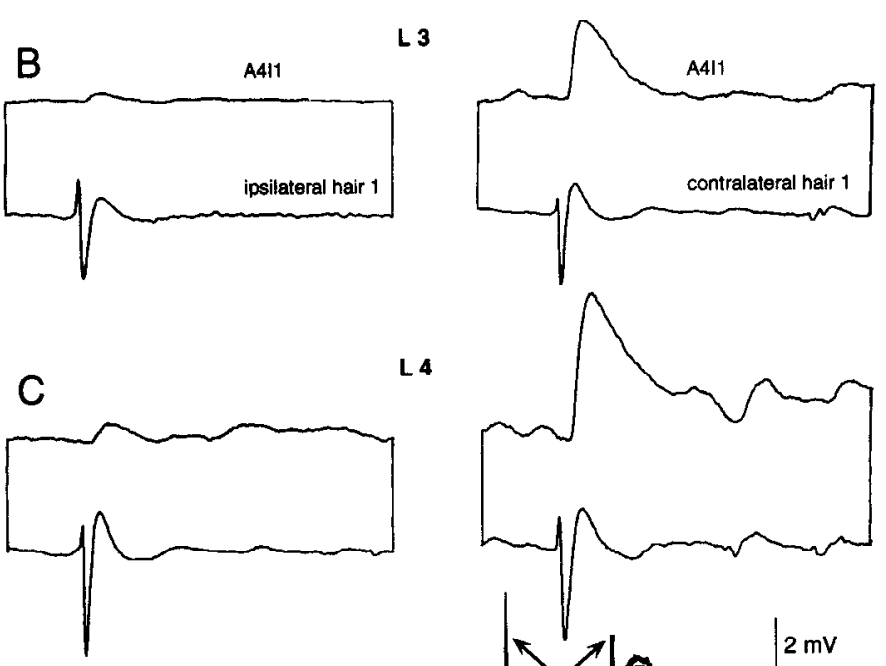

L4

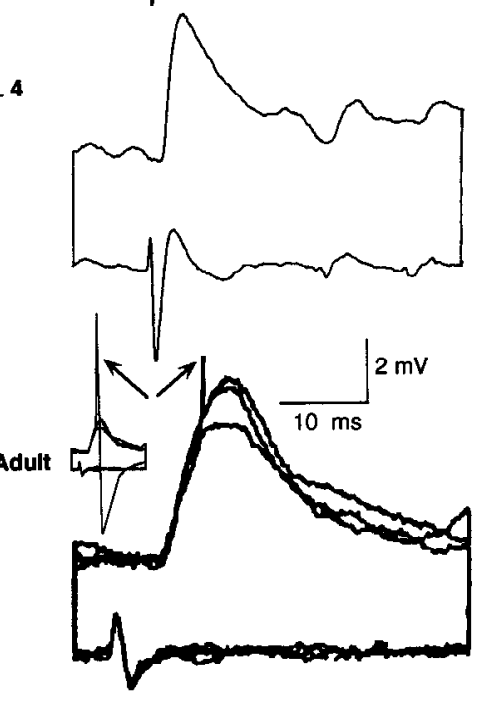

Figure 5. Connections of prosternal hair afferents with the A4I1 interneurons. $A$, Recording arrangement from the axon of an A4I1 interneuron and from the two hairs in an adult animal. $B-D$, Connections of left (ipsilateral) and right (contralateral) ventral filiform hairs 1 with the left $\mathrm{A} 4 \mathrm{I} 1$ in the third $(L 3)$ and fourth $(L 4)$ instar, and in the adult. Upper traces show intracellular record from A4I1, and lower traces, the respective sensory spike recorded extracellularly from the cut hair shaft. Recordings in $B$ and $C$ are a verages ( 100 sweeps triggered by the afferent spikes) and in $D$ four traces are superimposed (from Pflüger and Burrows, 1990), the arrow showing the onset of an A4I1 spike that is fully shown in the inset.

nates their ipsilateral branches, and their synaptic connections with the ipsilateral A4I1 interneuron. In the absence of this activity, the ipsilateral branch and its synapses survive. In these experiments, activity of hairs on one-half of the ventral basisternum and on one lateral episternum was blocked. The next set of experiments was designed to test whether blocking the activity of the hairs on one episternum alone is sufficient to induce the changes.

Immobilizing the right lateral hairs. Lateral filiform hairs on the right proepisternum were covered with wax in all instars and the projections of their sensory neurons were stained in adults (Fig. 7). Fourteen ventral hairs were stained on the right probasisternum, ipsilateral to the manipulated right lateral proepisternum, and of these, $71 \%$ had both ipsi- and contralateral projections and the remaining $29 \%$ only contralateral projections (Fig. $8 A$, fourth column). Again, in Figure 7, $A$ and $B$ show
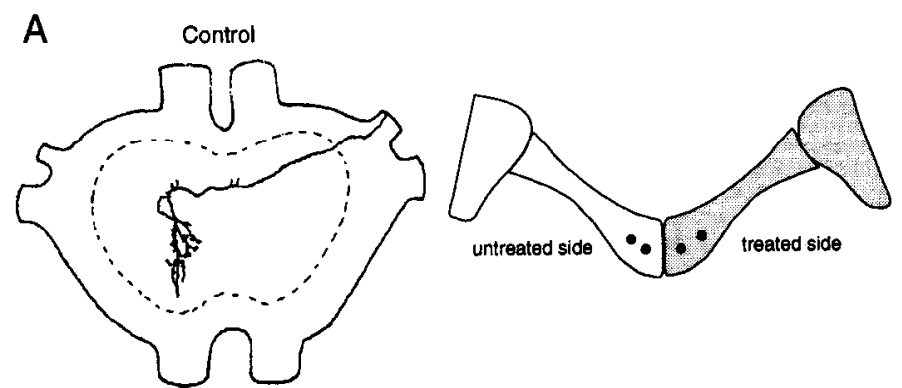

B

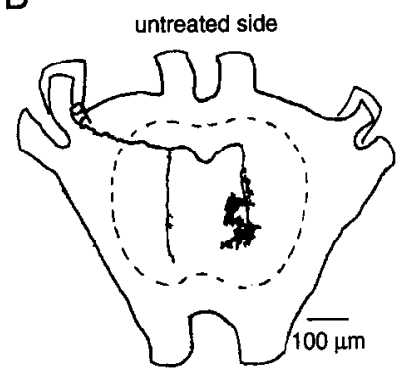

D
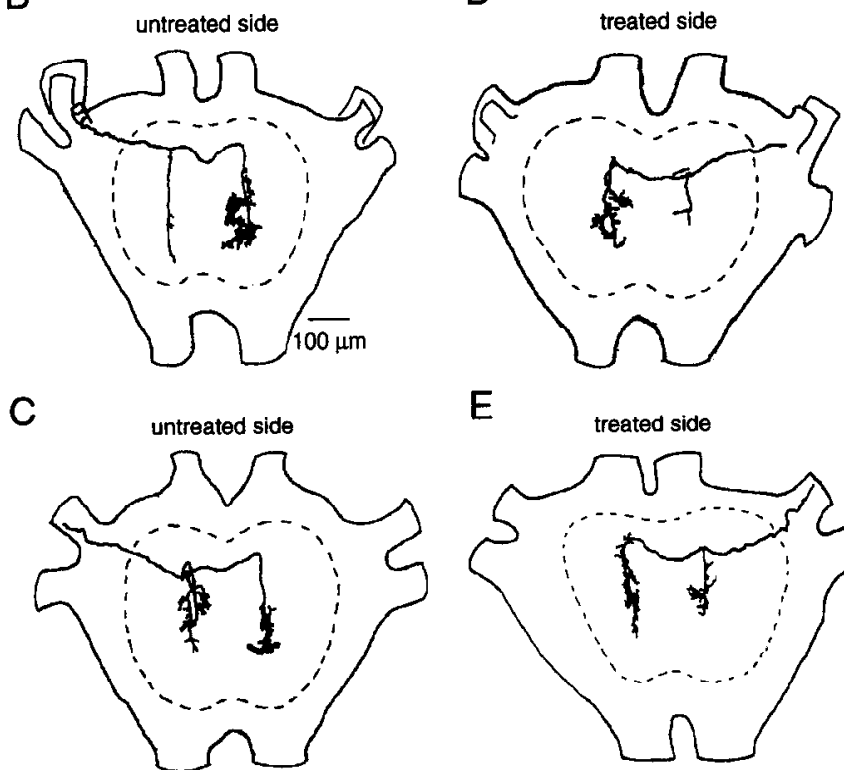

E

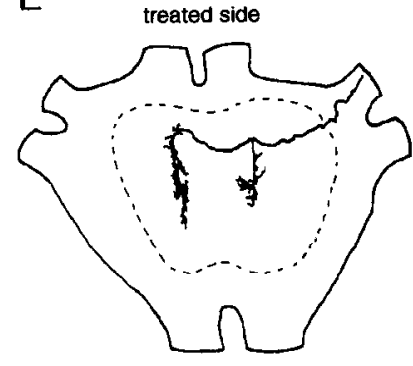

Figure 6. Disruption of normal development. A, Projection of a ventral hair in a normal animal as a control. The diagram shows the manipulated area (shaded) on the prosternum (right proepisternum and right probasisternum) and black dots mark position of hairs. Central projections of ventral filiform hair afferents from untreated $(B$ and $C)$ and treated side $(D$ and $E)$ in adults.

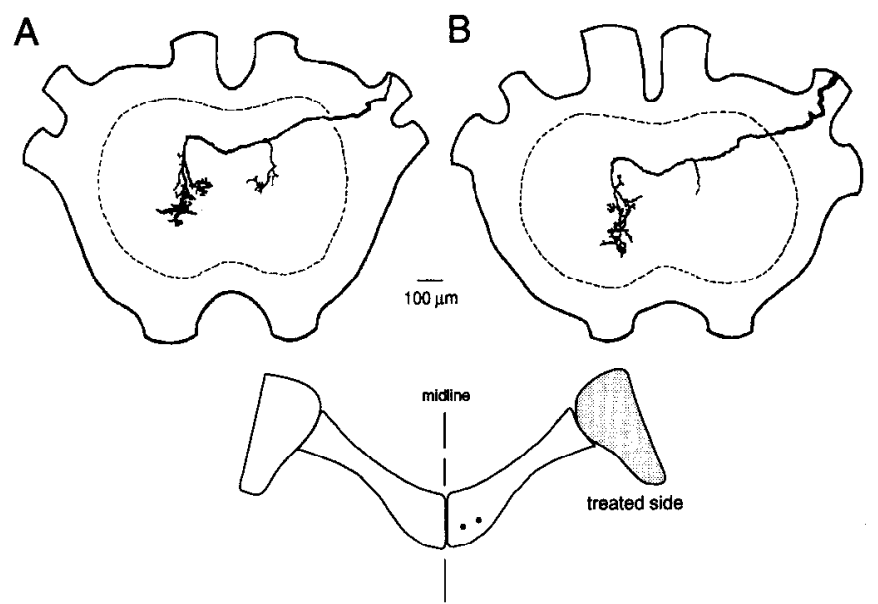

Figure 7. Disruption of normal development. $A$ and $B$, Central projections of ventral filiform hair afferents from untreated probasisternum (black dots in inset mark position of hairs) adjacent to treated right proepisternum (shaded area in inset). 

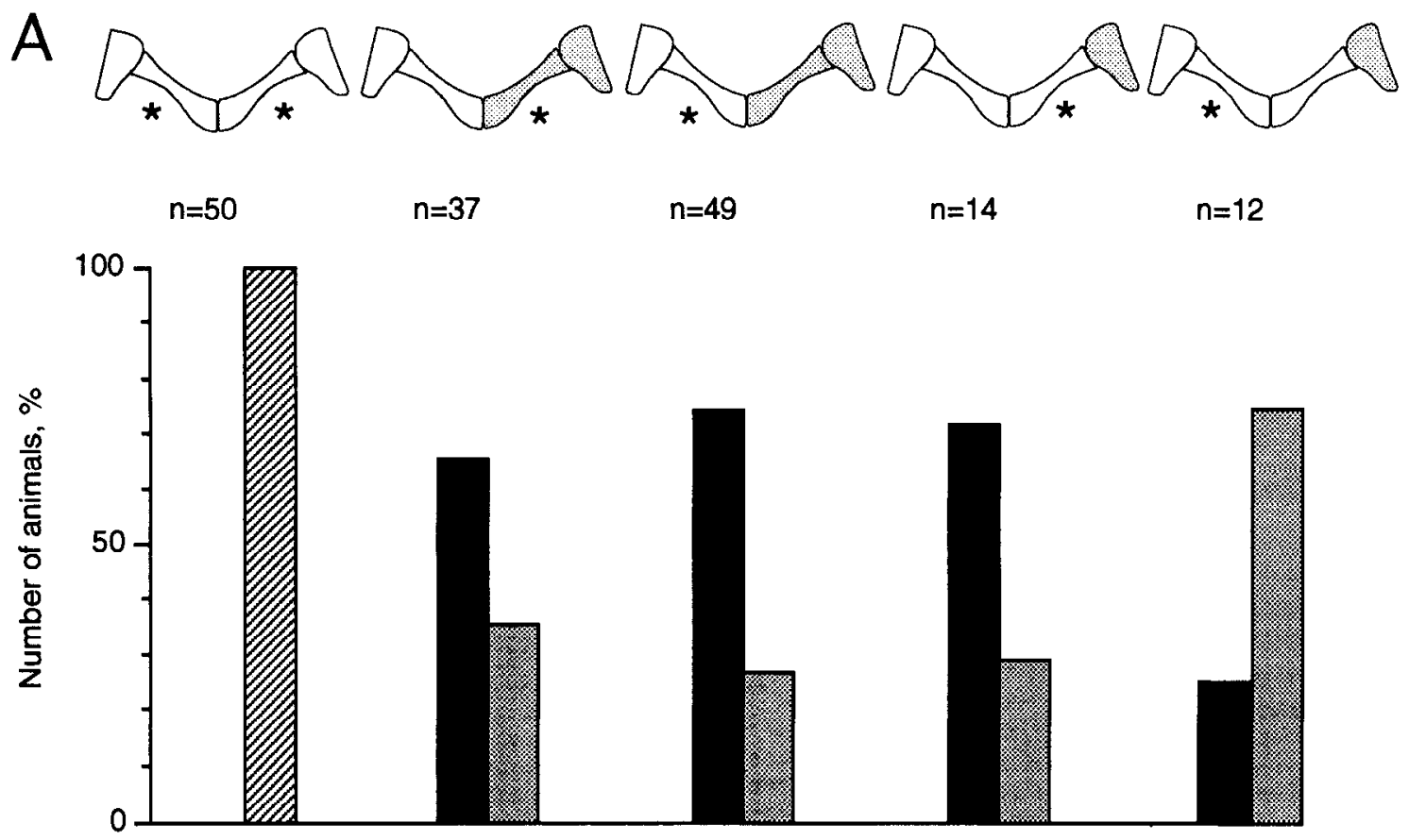

Projection with ipsi- and contralateral branches

Projection with contralateral branch only

B $\quad \begin{aligned} & \text { Control } \\ & n=10\end{aligned} \quad n=10 \quad n=10 \quad n=7 \quad n=3$

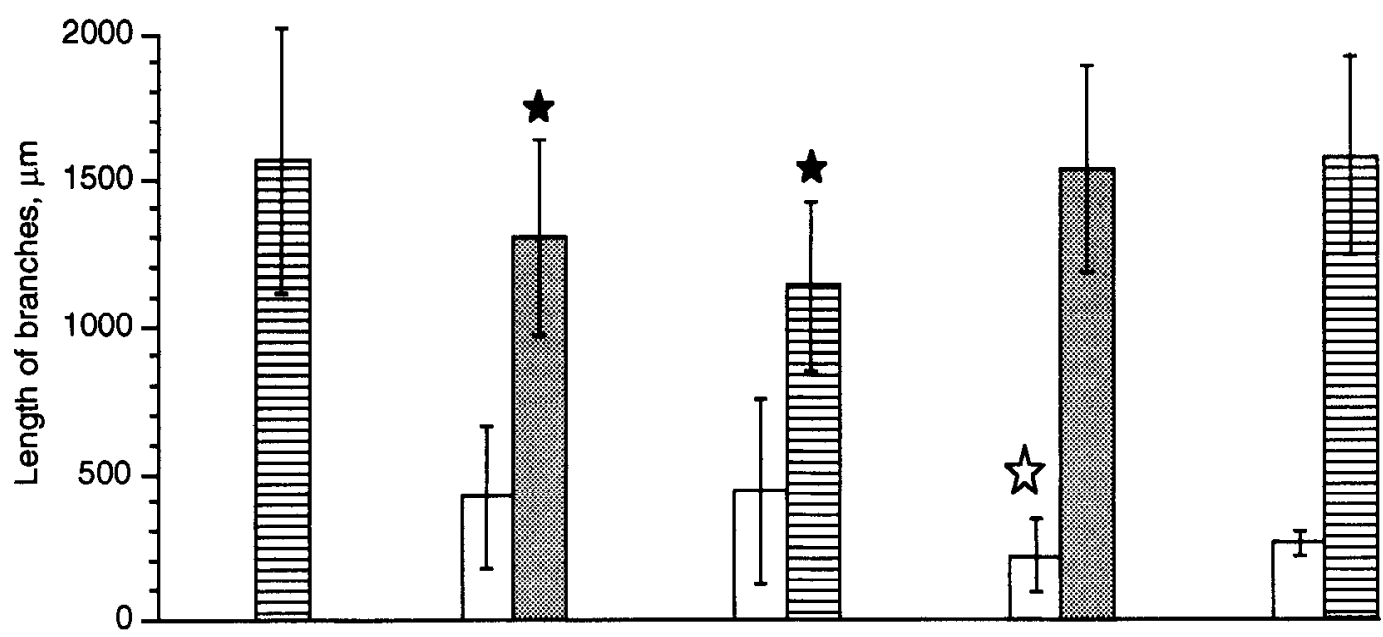

Length of ipsilateral branches

Length of contralateral branches

Figure 8. Quantitative measurements of the afferent projections. $A$, Number of animals in which specific treatments were performed. In each animal one hair was stained. In column 1 , no treatments were performed and all hairs in the position marked with the asterisk had only projections with contralateral branches. The other columns represent the effects of specific treatments indicated in the diagram at the top of each column. $B$, Total length of afferent branches in the treatments given in $A$. The right four columns are measurements of those hairs with both ipsilateral and contralateral branches (black columns in A). Solid stars indicate significant differences $(p<0.05)$ to controls $($ first column). Open star indicates significant difference at $p<0.1$. Columns and error bars show mean values and standard deviations. 
the extreme projections of ipsi- and contralateral branches, one with a well-developed ipsilateral branch (Fig. $7 A$ ) and the other with only a small naked collateral remaining (Fig. $7 B$ ). On the left probasisternum contralateral to the manipulated area, however, $75 \%$ of ventral hairs had only contralateral projections (data from 12 hairs) and thus resembled those of control animals (Figs. $6 A ; 8 A$, fifth column), whereas the remaining $25 \%$ had both ipsilateral and contralateral projections. Therefore, the results of these experiments are further support for activity-dependent interactions between afferent fibers.

\section{Quantitative measurements of total length of projections}

The projections were quantified by measuring the total length of the ipsi- and contralateral branches from the point of the $90^{\circ}$ posterior turn of the main axon (Fig. $8 B$ ). In control adults, the total length of the contralateral branches ranged from 1052 to $2517 \mu \mathrm{m}(1571 \pm 454 \mu \mathrm{m}$, mean $\pm \mathrm{SD} ; n=10)$. In experimental animals whose right ventral and lateral hairs were immobilized, ventral hair afferents of the treated side had ipsilateral branches that ranged in length from 125 to $861 \mu \mathrm{m}(418 \pm 243 \mu \mathrm{m} ; n=$ $10)$, and contralateral branches, from 870 to $1889 \mu \mathrm{m}$ (1306 \pm $333 \mu \mathrm{m} ; n=10$ ). For ventral hair afferents of the untreated side, the total length of the ipsilateral axon ranged from 74 to 1083 $\mu \mathrm{m}(438 \pm 318 \mu \mathrm{m} ; n=10)$, and the contralateral branch, from $611 \mu \mathrm{m}$ to $1472 \mu \mathrm{m}(1135 \pm 284 \mu \mathrm{m} ; n=10)$. In experimental animals that had lateral hairs immobilized on one side, ventral hair afferents ipsilateral to the manipulated area had ipsilateral branches that ranged in length from 89 to $418 \mu \mathrm{m}(213 \pm 128$ $\mu \mathrm{m} ; n=7)$, and contralateral branches, from 914 to $1844 \mu \mathrm{m}$ (1532 $\pm 352 \mu \mathrm{m} ; n=7$ ). Those on the side contralateral to the manipulated area had ipsilateral branches measuring $259 \pm 37$ $\mu \mathrm{m}(n=3)$ in length, and contralateral projections that measured $1584 \pm 336 \mu \mathrm{m}(n=3)$. Application of a Wilcoxon, MannWhitney $U$ test shows that with respect to the length of the contralateral branch, only the bars marked with a star (second and third columns in Fig. $8 B$ ) are significantly different $(p<$ 0.05 ) from the control length of contralateral branches (First column in Fig. $8 B$ ). No significant differences could be found between the length of ipsilateral branches, although the length of the branch marked with an open star was significantly different at a level of $p<0.1$. We conclude, therefore, that when the central projection of a ventral hair retains a pronounced ipsilateral branch, the surviving contralateral branch does not attain its full arborization.

\section{Discussion}

This study has shown that in undisturbed normal development the axonal branches of afferent neurons from particular identified ventral filiform hairs invade the ipsi- and contralateral neuropil in early instars and then withdraw from the ipsilateral neuropil in subsequent instars, until in the adult only the contralateral projection remains. This change in the anatomy is paralleled by changes in the connections made by these afferents with an identified interneuron (A4I1). Synapses are first made with both ipsilateral and contralateral interneurons, but only the contralateral synapses remain in the adult. The withdrawal of branches, and the accompanying loss of synapses, is dependent on afferent activity. Blocking the afferent activity during larval instars prevents withdrawal of the ipsilateral branches. We would predict that this is also accompanied by the persistence of synapses with the ipsilateral interneuron, although this has not yet been tested physiologically.

\section{Role of activity in the developmental changes}

The reasons for suggesting that activity plays an important role during refinement in normal development of the locust prosternal hairs are the following. First, immobilizing the hairs completely blocked the activity of afferents, which in intact animals spike to wind speeds as low as $27.5 \pm 6.2 \mathrm{~mm} / \mathrm{sec}$ (Pflüger and Tautz, 1982). Following both types of treatments used, only strong tactile stimuli generated bursts of spikes in the afferents. It is unlikely that an experimental locust would have experienced such stimuli when walking freely in its cage. Second, our manipulations did not disturb the sensory neuron and the accessory cells of each filiform hair, as after each molt a full complement of filiform hairs still appeared on the treated side. This indicates that each filiform hair retained its peripheral position. This is important because on the cerci of crickets and cockroaches the peripheral position of a hair determines its central projection pattern (Kämper and Murphey, 1987; Blagburn et al., 1991; Thompson et al., 1992). Third, there were no indications that the hormonal environment in treated animals differed from untreated control groups. In holometabolous insects, neurite retraction and growth during metamorphosis are controlled by hormones (Levine and Weeks, 1989, 1990; Weeks and Levine, 1990).

The manipulations failed to affect about $30 \%$ of examined afferent projections, perhaps because in some animals there was a delay of up to $16 \mathrm{hr}$ between the end of a molting cycle and renewed treatment of filiform hairs on the new cuticle. During these hours, filiform hairs could function normally again because mechanoreceptors are only briefly insensitive during molting and fully functional once the hair shaft is erected (Gnatzy and Tautz, 1977). If this is the explanation, then it suggests that a certain duration of activity is required for inducing the structural changes, similar to the sensitive periods in the development of visual systems in mammals (Hubel and Wiesel, 1970).

\section{Behavioral considerations}

The changing pattern of the afferent arborizations of locust prosternal hairs and their synaptic connections means that the receptive field of the A4I1 interneurons is different in larvae and adults. The reason for this change may be sought in their function during flight steering of adults. Although only adult animals possess fully functional wings, the principal wiring of the flight motor is already present in a first larval instar (Stevenson and Kutsch, 1986, 1988), and some sensory-to-motoneuron connections also exist in early instars (Heathcote, 1980, 1981). Nevertheless, maturation of circuits is occurring, but the function of established connections of the prosternal hairs is not known in larvae. Furthermore, it is not known whether changes also occur in the structure and connectivity in the flight interneurons during larval development. Preliminary stains of the A4I1 interneuron in larvae have not revealed dramatic changes in structure, except the growth of side branches. This corresponds to the findings for other interneurons such as a descending visual interneuron in locusts (Bentley and Toroian-Raymond, 1981), and a giant ascending mechanoreceptive interneuron in cockroaches (Blagburn and Beadle, 1982) and grasshoppers (Shankland and Goodman, 1982) does not reveal dramatic structural changes during development.

\section{Comparison with other systems}

The remodeling of synapses during postembryonic development described here shows some similarities to that of the cercal 
filiform hairs in crickets (Murphey et al., 1984; Murphey, 1986b) and cockroaches (Blagburn and Beadle, 1982, 1984; Blagburn et al., 1986; Blagburn, 1989). In the cercal system, however, the sensory fibers "achieve their final branching pattern with a minimum of overgrowth and pruning" (Shankland, 1981a,b). Although the connectivity of cercal afferents changes dramatically, they do not lose distinct axonal branches, but instead shift the distribution of varicosities and density of side branches (Chiba et al., 1988, 1992). In early larval instars, when a cercal filiform hair is short, it makes a strong synapse with the MGI interneuron (medial giant interneuron), which decreases in strength as the hair grows longer in later instars, until in the adult this connection can no longer be detected (Chiba et al., 1988). By contrast, the synapse between these hairs and another interneuron, called 10-3, increases in strength as the hair growths longer. Therefore, there is a dramatic shift in target interneuron from MGI to 10-3 for a particular receptor. The reason for this shift is probably that MGI codes for acceleration, and shorter hairs respond best to acceleration of the stimulus, whereas 10-3 codes for velocity, and longer hairs respond best to velocity (Shimozawa and Kanou, 1984; Chiba et al., 1988). In the system examined here, the target neuron remains the same throughout development, but its receptive field is refined by loss and strengthening of synapses.

A remarkable similarity between this invertebrate (insect) system and vertebrate systems is that neuronal activity is required for the segregation of fibers during normal development. In goldfish and cats, segregation of fibers and subsequent loss of synapscs can be prevented by blocking neuronal activity by application of tetrodotoxin (Archer et al., 1982; Meyer, 1982; Schmidt and Edwards, 1983) or suturing one eye (Wiesel and Hubel, 1963; Hubel and Wiesel, 1970). Similar activity-dependent mechanisms have also been suggested for the development of the cortical barrel fields associated with whiskers of rats (Schlaggar et al., 1993).

\section{Competition between receptors}

Although interactions between the identified target interneuron and the afferent terminals cannot be ruled out, the prosternal hair system may provide an excellent opportunity to study competitive interactions. We have to assume that the interactions between the sensory fibers of prosternal hairs are of a different kind because in other models of competition silenced axons lose in competition with normally active axons (review, Guillery, 1988). In the prosternal hair systcm, reduced competition, achieved by dramatically altering if not silencing completely the activity of some afferent fibers, prevents structural changes that would otherwise occur in normal competition. Blocking the activity of ventral and lateral filiform hair afferents on one side of the prosternum alters the projections of afferents from both the untreated and treated ventral sides. In both, the survival of the ipsilateral branches can be explained by decreased competitive interactions, because afferent activity had been removed during development. The retention of their ipsilateral branches by afferents of the treated ventral side suggests that blocking the activity of lateral filiform hairs alone is sufficient to alter these competitive interactions. Indeed, when activity of these lateral hairs alone was blocked, the ipsilateral branches of ventral afferents predominantly survived only in these neuropils that were contacted by the projections of the lateral afferents. We suggest, therefore, (1) that the lateral hairs that have only ipsilateral projections are strong competitors for the contralateral projections, and (2) that their "competitive potency" is very much reduced when their activity has been suppressed in larval instars. In addition, we assume that the ventral hairs have full "competitive potency" only after loss of their ipsilateral branch. This is supported by measurements of the total length of contralateral branches, which is significantly smaller when a pronounced ipsilateral branch is present (Fig. 8). There are indications, therefore, that activity-dependent competitive interactions between afferent terminals shape the final axonal branches of sensory neurons. This prosternal hair system will now allow us to immobilize single identified hairs and study the effects on the structure and connections of their immediatc ncighbors.

\section{References}

Albrecht FO (1953) The anatomy of the migratory locust. London: Athlone.

Archer SM, Dubin MW, Stark LA (1982) Abnormal development of kitten retino-geniculate connectivity in the absence of action potentials. Science 217:743-745.

Bacon JP, Altman JS (1977) A silver intensification method for cobaltfilled neurones in wholemount preparations. Brain Res 138:359-363.

Bentley D, Toroian-Raymond A (1981) Embryonic and postembryonic morphogenesis of a grasshopper interneuron. J Comp Neurol 201:507-518.

Blagburn JM (1989) Synaptic specificity in the first instar cockroach: patterns of monosynaptic input from filiform hair afferents to giant interneurons. J Comp Physiol [A] 166:133-142.

Blagburn JM, Beadle DJ (1982) Morphology of identified cercal afferents and giant interneurones in the hatchling cockroach Periplaneta americana. J Exp Biol 97:421-426.

Blagburn JM, Beadle DJ (1984) Synapses between an identified giant interneurone and a filiform hair sensory neurone in the terminal ganglion of first instar cockroaches (Periplaneta americana L). J Exp Biol $113: 477-481$.

Blagburn JM, Beadle DJ, Sattelle DB (1986) Differential synaptic input of filiform hair sensory neurones on to giant interneurones in the firstinstar cockroach. J Insect Physiol 32:591-595.

Blagburn JM, Blanco RE, Thompson KSJ, Bacon JP (1991) Positional information determines the anatomy and synaptic specificity of cockroach filiform hair afferents using independent mechanisms. J Comp Physiol [A] 169:607-614.

Brown MC, Jansen JKS, Van Essen DC (1976) Polyneuronal innervation of skeletal muscle in new-born rats and its elimination during maturation. J Physiol (Lond) 261:387-422.

Burrows M, Pflüger H-J (1992) Output connections of a wind sensitive interneurone with motor neurones innervating flight steering muscles in a locust. J Comp Physiol [A] 171:473-446.

Chiba A, Murphey RK (1991) Connectivity of identified central synapses in the cricket is normal following regeneration and blockade of presynaptic activity. J Neurobiol 22:130-142.

Chiba A, Shepherd D, Murphey RK (1988) Synaptic rearrangement during postembryonic development in the cricket. Science 240:901905.

Chiba A, Kämper G, Murphey RK (1992) Response properties of interneurons of the cricket cercal sensory system are conserved in spite of changes in peripheral receptors during maturation. J Exp Biol 164:205-226.

Crepel F, Mariani F, Delhaye-Bouchaud D (1976) Evidence for a multiple innervation of purkinje cells by climbing fibers in the immature rat cerebellum. J Neurobiol 7:567-578.

Easter SSJ, Purves D, Rakic P, Spitzer NC (1985) The changing view of neural specificity. Science 230:507-511.

Gao W-Q, Macagno ER (1987a) Extension and retraction of axonal projections by some developing neurons in the leech depends upon the existence of neighboring homologues. I. The HA cells. J Neurobiol 18:43-59

Gao W-Q, Macagno ER (1987b) Extension and retraction of axonal projections by some developing neurons in the leech depends upon the existence of neighboring homologues. II. The AP and AE neurons. J Neurobiol 18:295-313. 
Gnatzy W, Tautz J (1977) Sensitivity of an insect mechanoreceptor during moulting. Physiol Entomol 2:279-288.

Goldman-Rakic PS (1981) Prenatal formation of cortical input and development of cytoarchitectonic compartments in the neostriatum of the rhesus monkey. J Neurosci 1:721-735.

Goodman CS, Shatz CJ (1993) Developmental mechanisms that generate precise patterns of neuronal connectivity. Neuron [Suppl] 10: 77-98.

Guillery RW (1988) Competition in the development of the visual pathways. In: The making of the nervous system (Parnavelas JG, Stern CD, Stirling RV, eds), pp 356-379. London: Oxford UP.

Heathcote RD (1980) Physiological development of a monosynaptic connection involved in an adult insect behavior. J Comp Neurol 191: $155-166$.

Heathcote RD (1981) Differentiation of an identified sensory neuron (SR) and associated sensory structures (CTO) in grasshopper embryos. J Comp Neurol 202:1-18.

Hodgson ES, Lettvin JY, Roeder KD (1955) Physiology of a primary chemoreceptor unit. Science 122:417-418.

Hubel DH, Wiesel TN (1963) Shape and arrangement of columns in cat's striate cortex. J Physiol (Lond) 165:559-568.

Hubel DH, Wiesel TN (1970) The period of susceptibility to the physiological effects of unilateral eye closure in kittens. J Physiol (Lond) 206:419-436.

Jackson H, Parks TN (1982) Functional synapse elimination in the developing avian cochlear nucleus with simultaneous reduction in cochlear-nerve axon branching. J Neurosci 2:1736-1743.

Kämper G, Murphey RJ (1987) Synapse formation by sensory neurons after cross-species transplantation in crickets: the role of positional information. Dev Biol 122:492-502.

Kuwada JY, Kramer AP (1983) Embryonic development of the leech nervous system: primary axon outgrowth of identified neurons. $J$ Neurosci 3:2098-2111.

LeVay S, Stryker MP, Shatz CJ (1978) Ocular dominance columns and their development in layer IV of the cat's visual cortex. I Comp Neurol 179:223-244.

LeVay S, Wiesel TN, Hubel DH (1980) The development of ocular dominance columns in normal and visually deprived monkeys. $J$ Comp Neurol 191:1-51.

Levine RB, Weeks JC (1989) Reorganization of neural circuits and behavior during insect metamorphosis. In: Perspectives in neural systems and behavior, pp 195-228. New York: Liss.

Levine RB, Weeks JC (1990) Hormonally mediated changes in simple reflex circuits during metamorphosis in Manduca. $\mathrm{J}$ Neurobiol 2l: 1022-1036.

Lnenicka GA, Atwood HL (1985) Age dependent long-term adaptation of crayfish phasic motor axon synapses to altered activity. J Neurosci 5:459-467.

Lnenicka GA, Murphey RK (1989) The refinement of invertebrate synapses during development. J Neurobiol 20:339-355.

Lnenicka GA, Atwood H, Marin L (1986) Morphological transformation of synaptic terminals of a phasic motoneuron by long-term tonic stimulation. J Neurosci 6:2252-2258.

Lnenicka GA, Hong SJ, Combatti M, LePage S (1991) Activity-dependent development of synaptic varicosities at crayfish motor terminals. J Neurosci 11:1040-1048.

Meyer RT (1982) Tetrodotoxin blocks the formation of ocular dominance in goldfish. Science 218:589-591.

Murphey RK (1986a) The myth of the inflexible invertebrate: competition and synaptic remodelling in the development of invertebrate nervous systems. J Neurobiol 16:585-591.

Murphey RK (1986b) Competition and the dynamics of axon arbor growth in the cricket. J Comp Neurol 251:100-110.

Murphey RK, Lemere CA (1984) Competition controls the growth of an identified axonal arborization. Science 224:1353-1354.

Murphey RK, Walthall WW, Jacobs GA (1984) Ncurospecificity in the cricket cercal system. J Exp Biol 112:7-25.

Pahapill PA, Lnenicka GA, Atwood HL (1985) Asymmetry of motor impulses and neuromuscular synapses produced in crayfish claws by unilateral immobilization. J Comp Physiol [A] 157:461-467.
Pflüger H-J (1980) Central nervous projections of sternal trichoid sensilla in locusts. Naturwissenschaften 67:316-317.

Pflüger H-J (1984) The large fourth abdominal inter-segmental interneurone: a new type of wind-sensitive ventral cord interneuron in locusts. J Comp Neurol 222:343-357.

Pflüger H-J, Burrows M (1990) Synaptic connections of different strength between wind-sensitive hairs and an identified projection interneuron in the locust. Eur J Neurosci 2:1040-1050.

Pflüger H-J, Tautz J (1982) Air movement sensitive hairs and interneurones in Locusta migratoria. J Comp Physiol [A] 145:369-380.

Purves D, Lichtman JW (1980) Elimination of synapses in the developing nervous system. Science 210:153-157.

Purves D, Lichtman JW (1985) Principles of ncural devclopment. Sunderland, MA: Sinauer.

Redfern PA (1970) Neuromuscular transmission in new-born rats. J Physiol (Lond) 209:701-709.

Schlaggar BL, Fox K, O'Leary DDM (1993) Postsynaptic control of plasticity in developing somatosensory cortex. Nature 364:632-626.

Schmidt JT, Edwards DL (1983) Activity sharpens the map during the regeneration of the retinotectal projection in goldfish. Brain Res 269:29-39.

Shankland M (1981a) Development of a sensory afferent projection in the grasshopper embryo. I. Growth of peripheral pioneer axons within the central nervous system. J Embryol Exp Morphol 64:169185.

Shankland M (1981b) Development of a sensory afferent projection in the grasshopper embryo. II. Growth and branching of peripheral sensory axons within the central nervous system. J Embryol Exp Morphol 64:187-209.

Shankland M, Goodman CS (1982) Development of the dendritic branching pattern of the medial giant interneuron in the grasshopper embryo. Dev Biol 92:489-506.

Shatz CJ, Stryker MP (1978) Ocular dominance in layer IV of the cat's visual cortex and the effects of monocular deprivation. J Physiol (Lond) 281:267-283.

Shepherd D, Murphey RK (1986) Competition regulates the efficacy of an identified synapse in crickets. J Neurosci 6:3152-3160.

Shimozawa T, Kanou M (1984) Varieties of filiform hairs: range fractionation by sensory afferents and cercal interneurons of a cricket. $J$ Comp Physiol [A] 155:485-493

Stevenson PA, Kutsch W (1986) Basic circuitry of an adult specific motor program completed with embryogenesis. Naturwissenschaften 73:741-742.

Stevenson PA, Kutsch W (1988) Demonstration of functional connectivity of the flight motor system in all stages of the locust. J Comp Physiol [A] 162:247-259.

Thompson KSJ, Blagburn JM, Gibbon CR, Bacon JP (1992) Correlation of filiform hair position with sensory afferent morphology and synaptic connections in the second instar cockroach. J Comp Neurol 320:213-227.

Thompson WJ (1983) Synapse elimination in neonatal rat muscle is sensitive to pattern of muscle use. Nature 302:614-616.

Thompson WJ (1986) Changes in the innervation of mammalian skeletal muscle fibers during postnatal development. Trends Neurosci 9:25-28.

Wallace BG (1984) Selective loss of neurites during differentiation of cells in the leech central nervous system. J Comp Neurol 228:149153

Watson AHD, Pflüger H-J (1984) The ultrastructure of prosternal sensory hair afferents within the locust central nervous system. Neuroscience 11:269-279.

Weeks JC, Levine RB (1990) Postembryonic neuronal plasticity and its hormonal control during insect metamorphosis. Annu Rev Neurosci 13:183-194.

Wiesel TN, Hubel DH (1963) Effects of visual deprivation on morphology and physiology of cells in the cat's lateral geniculate body. $J$ Neurophysiol 26:978-993. 